\title{
Association of amyloidosis cutis dyschromica and familial Mediterranean fever*
}

\author{
Asli Akin Belli ${ }^{1}$ \\ Yelda Dere ${ }^{2}$
}

\author{
Asude Kara ${ }^{1}$ \\ Nevin Yilmaz ${ }^{3}$
}

DOI: http:/ /dx.doi.org/10.1590/abd1806-4841.20176114

\begin{abstract}
Amyloidosis cutis dyschromica is a rare type of primary cutaneous amyloidosis characterized by reticulate hyperpigmentation with discrete hypopigmented macules. Up to date, about 50 cases of amyloidosis cutis dyschromica have been reported and the majority are familial cases of Asian ethnicity. Various diseases, particularly autoimmune diseases such as systemic sclerosis and systemic lupus erythematosus, have been associated with amyloidosis cutis dyschromica. Herein, we report a case of amyloidosis cutis dyschromica accompanying familial Mediterranean fever with a delayed diagnosis of 40 years. To the best of our knowledge, this is the first report of the association of amyloidosis cutis dyschromica and familial mediterranean fever.
\end{abstract}

Keywords: Amyloidosis; Autoimmune diseases; Familial mediterranean fever; Pigmentation disorders

\section{INTRODUCTION}

Amyloidosis cutis dyschromica (ACD) is an uncommon type of primary cutaneous amyloidosis characterized by symmetric reticulate hyperpigmentation with guttate hypopigmented macules. After the first description of ACD by Morishima in 1970, approximately 50 cases of ACD have been reported. Although sporadic cases have been identified, familial cases are more common with a relatively early age of onset. ${ }^{1-6}$ Moreover, various ACD associated diseases have been reported previously. Herein, we report a case of ACD accompanying familial mediterranean fever (FMF) with the delayed diagnosis of 40 years.

\section{CASE REPORT}

A 62-year-old Turkish female presented with darkening of all her skin for about 40 years. On physical examination, general- ized reticulate hyperpigmented patches and discrete hypopigmented macules, which were predominant on the back, upper chest, lumbar areas, elbows, and knees, were observed (Figure 1). The hyperpigmentation had increased gradually and spread to almost the whole body for the last two years. In the medical history, the patient had associated intermittent arthralgia and abdominal pain for about 40 years as well. Laboratory examinations were normal. Two punch biopsy specimens were obtained from the skin lesions. Histopathological examination showed amorphous, eosinophilic deposits in the papillary dermis. Crystal violet stain was positive, compatible with amyloidosis (Figure 2). After detailed evaluation of intermittent abdominal pain, heterozygous mutation in MEFV gene was detected. The patient was diagnosed with FMF and $0.5 \mathrm{mg}$ colchicine three times a day was commenced. The patient's arthralgia

Work submitted on 03.06.2016

Approved by the Advisory Board and accepted for publication on 19.07.2016

* Work performed at the Mugla Sitki Kocman University Training and Research Hospital, Department of Dermatology Financial Support: None.

Conflict of Interests: None.

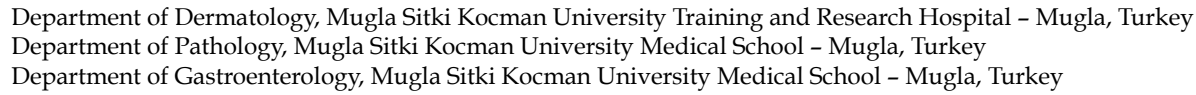


and abdominal pain have improved moderately with the colchicine therapy for a year, but the attempts of dosage reduction resulted in disease attacks. The skin lesions remained and even progressed in spite of topical therapy with steroids and retinoid. Interestingly, her daughter also had hyperpigmentation on her back for 6 months and was heterozygous for MEFV gene mutation. However, she refused to let us take a biopsy and pictures.

\section{DISCUSSION}

ACD is a rare type of primary cutaneous amyloidosis, which is common in Asian and particularly South-East Asian races. Specific characteristics of the disease were defined as follows: I reticular, dotted or diffuse hyperpigmented macules with guttate hypopigmented macules, II absence of pruritus or mild pruritus, and III, demonstration of amyloid deposition in the papillary dermis histopathologically. Skin involvement is generally symmetrical and progressive. Gender distribution is equal. Diagnosis of ACD is usually delayed because of the asymptomatic course. The differential diagnosis includes dyschromatosis universalis hereditaria, xeroder-
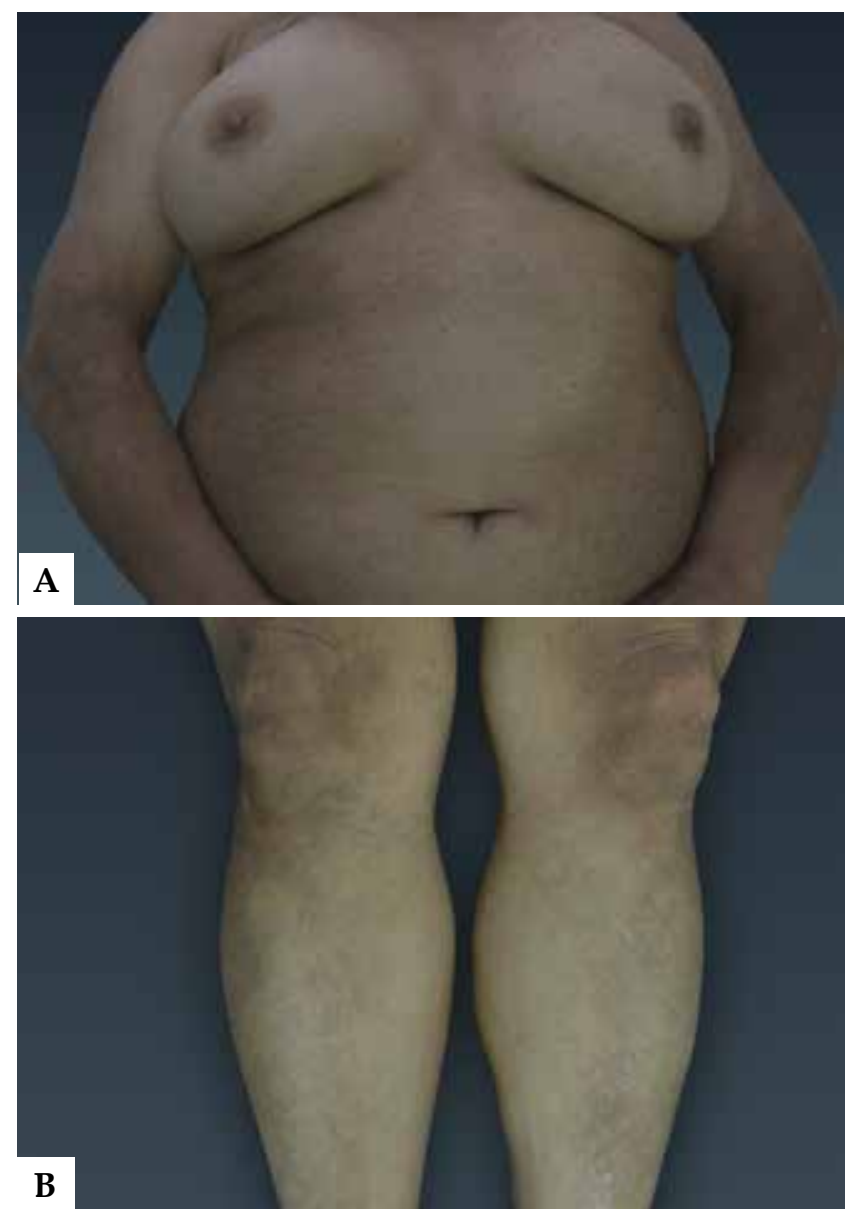

Figure 1: A. Generalized hyperpigmented patches with discrete hypopigmented macules on the upper chest, lumbar areas, elbows, and extensor sides of the upper limbs. B. Generalized reticulate hyperpigmentation with guttate hypopigmented macules especially on the knees, anterior sides of the legs and thighs ma pigmentosum, and poikyloderma-like cutaneous amyloidosis. ${ }^{1,2}$

In the pathogenesis of $\mathrm{ACD}$, genetic factors, immunology, and UV-induced damage of keratinocytes have been proposed. However, some of the reported cases including our patient have the lesions in areas not exposed to the sun. Consequently, it still remains unclear. Various diseases such as diabetes, hypertension, colon cancer, congenital pulmonary stenosis, systemic sclerosis, systemic lupus erythematosus, and Parkinsonism have accompanied ACD. ${ }^{1,2,4}$ In the treatment, topical $10 \%$ urea, tazarotene, oral antioxidants, and acitretin have been used. Only acitretin therapy has been found effective in some cases. ${ }^{1,5}$

FMF is an inherited auto-inflammatory disease resulting from MEFV gene mutation that is usually seen in people under 20 years old from the Mediterranean area. Diagnosis of FMF is based on clinical symptoms such as fever, arthritis, and abdominal pain, but the definitive diagnosis of FMF is made by the demonstration of MEFV gene mutation. Besides severe clinical presentations, some skin lesions have been reported with FMF. Cutaneous manifestations of FMF are rare. Erysipela-like erythema is the most common and well-known cutaneous manifestation that is seen as erythematous plaques in lower extremities concurrent to the disease attacks. Urticaria, edema, recurrent oral ulcers, erythema nodosum, recurrent bulla, and purpura are the other described cutaneous findings. ${ }^{7-9}$ To the best of our knowledge, our patient is the first case of ACD reported with FMF. Although renal amyloidosis is a well-defined complication of FMF, cutaneous amyloidosis related to FMF has not been reported previously. Amyloid types are amyloid light chain (AL) in primary systemic amyloidosis and amyloid A (AA) in secondary systemic amyloidosis as seen in FMF. Whereas macular amyloidosis and lichenoid amyloidosis are derived from keratin derivative amyloid, nodular amyloidosis is derived from AL type amyloid. ${ }^{10}$

Dahdah et al. stated that primary localized cutaneous amyloidosis is associated with various autoimmune disorders such as systemic sclerosis, rheumatoid arthritis, and systemic lupus erythematous. ${ }^{11}$ We do not know whether ACD in our patient is as-

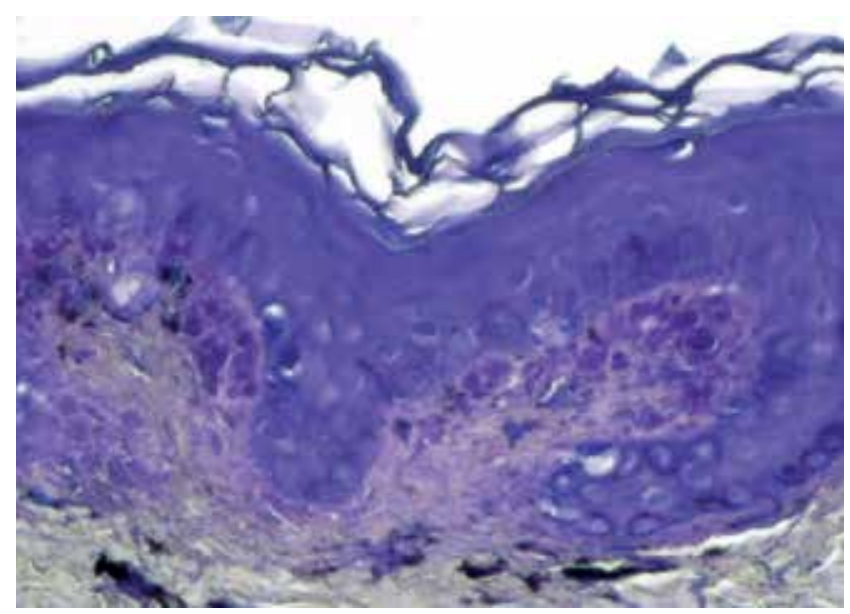

Figure 2: Positive staining of amyloid deposits with Crystal violet in the papillary dermis (Hematoxylin \& eosin, X200) 
sociated with FMF or coincidental. However, since FMF is also an auto-inflammatory disease, ACD in our patient may be due to the immune dysregulation, neutrophilic infiltration of the skin, and thus keratinocyte damage. Because her daughter had the same clinical presentation, the patient may be considered to have familial
ACD. The clinical course of FMF was progressive and response to the treatment was poor in our patient. Different cutaneous manifestations as we reported may provide information about the course of FMF and the current patient may contribute to the elucidation of the pathogenesis of ACD.]

\section{REFERENCES}

1. Mahon C, Oliver F, Purvis D, Agnew K. Amyloidosis cutis dyschromica in two siblings and review of the epidemiology, clinical features and management in 48 cases. Australas J Dermatol. 2015. doi: 10.1111/ajd.12342. [Epub ahead of print]

2. Yang W, Lin Y, Yang J, Lin W. Amyloidosis cutis dyschromica in two female siblings: cases report. BMC Dermatol. 2011;11:4.

3. Verma S, Joshi R. Amyloidosis Cutis Dyschromica: A Rare Reticulate Pigmentary Dermatosis. Indian J Dermatol. 2015;60:385-7.

4. Fernandes NF, Mercer SE, Kleinerman R, Lebwohl MG, Phelps RG. Amyloidosis cutis dyschromica associated with atypical Parkinsonism, spasticity and motor weakness in a Pakistani female. J Cutan Pathol. 2011;38:827-31.

5. Morales Callaghan AM, Vila JB, Fraile HA, Romero AM, Garcia GM. Amyloidosis cutis dyschromica in a patient with generalized morphoea. $\mathrm{Br} J$ Dermatol. 2004;150:616-7.

6. Ozcan A, Senol M, Aydin NE, Karaca S. Amyloidosis cutis dyschromica: a case treated with acitretin. J Dermatol. 2005;32:474-7.

7. Lidar M, Doron A, Barzilai A, Feld 0, Zaks N, Livneh A, et al. Erysipelas-like erythema as the presenting feature of familial Mediterranean fever. J Eur Acad Dermatol Venereol. 2013;27:912-5.

8. Akman A, Cakcak DS, Coban E, Ozbudak HI, Ciftcioglu MA, Alpsoy E, et al. Recurrent bullous lesions associated with familial Mediterranean fever: a case report. Clin Exp Dermatol. 2009;34:216-8.

9. Koné Paut I, Dubuc M, Sportouch J, Minodier P, Garnier JM, Touitou I. Phenotypegenotype correlation in 91 patients with familial Mediterranean fever reveals a high frequency of cutaneomucous features. Rheumatology (Oxford). 2000;39:1275-9.

10. Ritchie SA, Beachkofsky T, Schreml S, Gaspari A, Hivnor CM. Primary localized cutaneous nodular amyloidosis of the feet: a case report and review of the literature. Cutis. 2014;93:89-94.

11. Dahdah MJ, Kurban M, Kibbi AG, Ghosn S. Primary localized cutaneous amyloidosis: a sign of immune dysregulation? Int J Dermatol. 2009;48:419-21.

\author{
MAILING ADDRESS: \\ Asli Akin Belli \\ Mugla Sitki Kocman University, \\ Department of Dermatology \\ 48000, Mugla, Turkey. \\ E-mail:dr_asliakin@hotmail.com
}

How to cite this article: Akin Belli A, Kara A, Dere Y, Yilmaz N. Association of amyloidosis cutis dyschromica and familial Mediterranean fever. An Bras Dermatol. 2017;92(5 Suppl 1): 21-3. 